\title{
Atmospheric pressure X-ray photoelectron spectroscopy apparatus: Bridging the pressure gap
}

\author{
J. J. Velasco-Vélez ${ }^{1,2, *}$, V. Pfeifer ${ }^{2}$, M. Hävecker ${ }^{1, *}$, R. Wang ${ }^{3}$, A. Centeno ${ }^{4}$, A. Zurutuza ${ }^{4}$, G. Algara- \\ Siller $^{2}$, E. Stotz ${ }^{2}$, K. Skorupska ${ }^{1}$, D. Teschner ${ }^{2}$, P. Kube ${ }^{2}$, P. Braeuninger-Weimer, S. Hofmann, R. \\ Schlögl ${ }^{1,2}$ and A. Knop-Gericke ${ }^{2}$
}

*Corresponding authors: velasco@ fhi-berlin.mpg.de and mh@fhi-berlin.mpg.de

${ }^{1}$ Department of Heterogeneous Reactions, Max Planck Institute for Chemical Energy Conversion, Mülheim an der Ruhr 45470, Germany

${ }^{2}$ Department of Inorganic Chemistry, Fritz-Haber-Institut der Max-Planck-Gesellschaft, Berlin 14195, Germany

${ }^{3}$ Engineering Department, University of Cambridge, Cambridge CB3 0FA, United Kingdom

${ }^{4}$ Graphenea, San Sebastian 20018, Spain

\begin{abstract}
:
One of the main goals in catalysis is the characterization of solid/gas interfaces in a reaction environment. The electronic structure and chemical composition of surfaces become heavily influenced by the surrounding environment. However, the lack of surface sensitive techniques that are able to monitor these modifications under high pressure conditions hinders the understanding of such processes. This limitation is known throughout the community as the "pressure gap". We have developed a novel experimental setup that provides chemical information on a molecular level under atmospheric pressure and in presence of reactive gases and at elevated temperatures. This approach is based on separating the vacuum environment from the high-pressure environment by a silicon nitride grid-that contains an array of micrometer-sized holes-coated with a bilayer of graphene. Using this configuration, we have investigated the local electronic structure of catalysts by means of photoelectron spectroscopy, and in presence of gases at 1 atmosphere. The reaction products were monitored on-line by mass spectrometry and gas chromatography. The successful operation of this setup was demonstrated with three different examples: the oxidation/reduction reaction of iridium (noble metal) and copper (transition metal) nanoparticles and with the hydrogenation of propyne on Pd black catalyst (powder).
\end{abstract}

\section{Introduction}

Catalysis is a term introduced by Baron J. J. Berzelius in 1835 describing the property of some substances to increase the rate of reactions without being consumed themselves ${ }^{1}$. The most important catalytic effect is the increase of reaction rate by means of lowering the activation energy. Although the equilibrium between reactants and products is determined only by thermodynamics, catalysts allow equilibrium to be established quicker. Therefore, heterogeneous catalysis is extensively used in industrial processes to reduce operating temperatures and lower production costs ${ }^{2}$. Furthermore, catalysis represents the principal operation concept in different devices such as solid state sensors ${ }^{3}$, chemical separators ${ }^{4}$, solid oxide fuels cells ${ }^{5}$, and is used in biological applications ${ }^{6}$. Another important application area of catalysts is the treatment of greenhouse gases (GGs) and the mitigation of their effects ${ }^{7}$. The ultimate objective in catalysis 
research is to reach the ideal geometry and electronic properties of catalysts for a desired reaction. However, the analysis of the electronic surface structure under real operating conditions is one of the main challenges in heterogeneous catalysis.

X-ray based spectroscopy techniques provide fundamental information about the electronic structure of catalyst materials. However, since all of the X-ray-based methods that yield insight into the electronic structure of catalysts-in particular photoelectron spectroscopy (PES) as well as soft X-ray emission (XES) and X-ray absorption (XAS) spectroscopies in the soft rangerequire vacuum conditions, they are hardly compatible with gases at atmospheric pressures. The discrepancy between higher operating pressures applied in catalytic processes and lower measurement pressures accessible during surface characterization is known in the community as the "pressure gap" 8 . To bridge this gap, new experimental and instrumental methods have been developed such as Ambient Pressure XPS (AP-XPS), which allows the collection of photoelectrons at pressures in the millibar range ${ }^{9}$. The wealth of information provided by these experimental setups is of prime importance to the understanding of complex systems. However, the study of solid-gas interfaces with partial pressures beyond a few tens of millibars remains a major challenge. Recently, this technique was extended to higher kinetic energy (HAXPES). Notably, this approach combined with a small aperture nozzle increases the operation pressure up to 100 millibars ${ }^{10,11}$. The higher KEs reduce the scattering of photoelectrons in the gas phase and increase the inelastic mean free path in the solid, which allows deeper material profile analysis. In addition the inclusion of a shaped mesh lens allows the collection of high energy photons at higher pressures ${ }^{11}$.

The pressure reached by HAXPES can be overcome by using photon-in/photon-out (PIPO) techniques in the soft X-ray range with an information depth of a few hundred nanometers ${ }^{12}$. The penetration depth of X-rays in PIPO techniques permits separation of the 1 bar gas phase from the UHV chamber containing soft X-ray source and detector via a thin silicon nitride membrane and thus the study of the material of interest at atmospheric pressure. In fluorescence yield (FY) PIPO techniques provide bulk information due to the fact that the photon are less attenuated than electrons, while in photon in/electron techniques like total electron yield (TEY) provide surface/sub-surface information, due to the fact that the photons are less attenuated than electrons $^{13}$. Nonetheless, a complete understanding of chemical reactions requires the characterization of the chemical composition at the outermost interface. Additionally, the evaluation of a depth profile of species perpendicular to the surface is highly desirable. Such depth resolution enables the discrimination between species located close to the interface or in the bulk, which is not possible with PIPO techniques. This problem can be resolved by using photoelectron spectroscopy where the penetration depth can be tuned by changing the energy of the incoming photons creating photoelectrons of different kinetic energy and hence different degree of inelastic scattering in the solid. The photoelectron signal yields information about the interface structure with nanometer sensitivity as well as local potential energy variations. Hence, XPS can describe the surface composition, oxidation state and electronic structure in a depth 
resolved manner ${ }^{14}$. Here we introduce an atmospheric pressure X-ray photoelectron spectroscopy gas cell based on an array of micro holes coated with graphene that solves the mechanical stability problem of free standing graphene covering large open areas and still provides high transmission for low kinetic energy electrons (higher than $400 \mathrm{eV}$ ) combined with a high rate of fabrication reproducibility. The newly developed gas cell follows the concept introduced by Velasco-Vélez et $\mathrm{al}^{15}$ for an electrochemical in-situ flow liquid cell.

\section{Technical approach}

In presence of gases, inelastic scattering with gas molecules prevents the photoelectrons, that are generated by incoming X-rays, from being collected effectively. Figure 1a shows the AP-XPS end-station located at the ISISS ${ }^{16}$ beamline (BESSY II, Berlin). A photoelectron transparent membrane (graphene) was implemented in the gas cell to separate the atmospheric pressure inside the cell from the vacuum on the outside and to maintain UHV conditions in the analyzer (as shown in Figure 1d2). Using this approach a reaction gas cell was developed, allowing controlled dosing of reaction gases in a flow through scheme at 1 bar total pressure. Figure 1c shows the main-chamber, including the manipulator. The whole reaction cell is mounted in a precision-motion stage (manipulator) that can accurately be adjusted in the $\mathrm{x}, \mathrm{y}$ and $\mathrm{z}$ directions relative to the beam and analyzer entrance aperture ("nozzle"). In such a way, the sample can be adjusted to an optimal position. The base of the gas cell provides feedthroughs for electrical contacts, used to ground or bias the samples and connect the thermocouples. Measuring the sample drain current also becomes feasible. In this section the technical characteristics of this setup are described in detail.

\section{II.A. Gas cell: Flow controller, heater and temperature monitoring, gas analysis}

The gas feed into the cell is achieved via a stainless-steel tube inlet (see Figure 1c), and is regulated by Bronkhorst mass flow controllers (see Figure 1b). Basic estimation of the gas flows in the inlet and outlet gas cell lines suggests that there should not be a noticeable pressure drop between the pressure in the cell, the sample container and the outgoing tubing. Helium is fed into the cell via a mass flow controller as an inert balance gas, which allows the system to operate at atmospheric pressures with relative low partial pressures of other fed gases.

Figure 1c shows the main-chamber, including the manipulator and the laser heater. Heating of the sample can be provided by various means. Either by direct heating of the sample deposited on the membrane (e.g. by an IR laser) or by indirect methods like heating the incoming gas. Here, we describe an indirect laser heating that avoids large temperature gradients on the sample but still acts locally on the sample material. Heating of the sample is provided by an infrared laser ( $\mathrm{p}_{\max }=60 \mathrm{~W}, 808 \mathrm{~nm}$ ) equipped with an optical system that forms a uniform heating field of $5 \times 5 \mathrm{~mm}^{2}$ at the rear of the target. Using this approach a stainless-steel plate is heated with the IR source which heats the gas and therefore the sample is heated indirectly. The laser is located outside the manipulator and the leak-tightness and IR transmission is assured by a special 
viewport flange. This IR laser heating system has proven its reliable performance in several insitu electron spectroscopy set-ups developed in our group ${ }^{17}$. A stainless-steel plate is heated by the IR laser and a small part of cell volume is heated by radiation and gas convection (see Figure 1d). Temperature control can be achieved via two thermocouples placed in the vicinity of the sample surface and in the stainless-steel heating plate, respectively. The trends in the temperature in the hot-plate and in the sample depend on the laser optical power, and are indicated in Figure 2. Heating with a laser avoids the problems associated with thermo-resistors in which the resistive current forms stray magnetic fields.

The outlet gas line is connected directly to a fast gas-chromatograph (VARIAN $\mu$-GC CP4900 equipped with 4 independent detection channels), allowing the identification and quantification of chemical products of the catalytic reaction. In addition, a fraction of the outgoing gas stream is fed into an electron impact mass spectrometer to analyze its composition.

\section{II.B. Graphene membrane}

Figure 3a shows a sketch of the hole array grid coated with graphene, and a scanning electron microscopy (SEM) image of this grid coated graphene is shown in Figure 3b. The chemicalvapour deposited (CVD) graphene was grown on $\mathrm{Cu}$ foil and transferred to the $\mathrm{Si}_{3} \mathrm{~N}_{4}$ grids in the procedure described by Velasco-Vélez et al ${ }^{15}$. Using the gas-flow cell described in Figure $1 \mathrm{~d}$ a pressure of $\sim 10^{-6}$ mbar arouse in the main chamber during flowing gas at 1 atmosphere on the other side of the membrane. The pressure in the main-chamber is the same for a reference solid silicon wafer sample (200 $\mu \mathrm{m}$ thick) suggesting excellent sealing properties of the graphene layer. Furthermore, supplemental Figure S2 shows ${ }^{18}$ the lack of a peak related to the gas-phase collected at $350 \mathrm{eV} \mathrm{KE}$ during dosing $\mathrm{N}_{2}$ (red curve), which is a good indication of the leak tightness of these membranes. Since electron transmission of BLG is pretty reduced for very low Ekin ${ }^{19}$. In addition to traditional XAS operation in fluorescence yield (FY) mode, this approach also allows the detection of photo- and Auger electrons generated near the solid/gas interface.

\section{Experimental cases}

The performance of this setup was evaluated by model reactions with three different classes of materials: the oxidation-reduction of transition metal $(\mathrm{Cu})$ and noble metal (Ir) nanoparticles and the selective hydrogenation of alkynes into alkanes/alkenes on a powder catalyst (solid Pd black, from ALDRICH with a surface area $40-60 \mathrm{~m}^{2} / \mathrm{g}$, 99.95\% trace metal basis). These experiments were performed using the ISISS beamline of BESSY II (Berlin, Germany) as a tunable soft Xray source.

\section{III.A. Oxidation of noble metals: Ir}

Iridium nanoparticles of $2-5 \mathrm{~nm}$ size were sputter-deposited on bilayer graphene as the TEM image shows (see Figure 4b). Figure S2 indicates that KEs higher than $400 \mathrm{eV}$ are required to generate photoelectrons with enough energy to pass through the $\mathrm{BLG}^{18}$. Thus, the presence of 
Iridium on the side of graphene exposed to the HV (analyzer) was ruled out by collecting the Ir 4f spectra at different KEs. The membrane was mounted in the gas cell and different gas mixtures were flowed at a temperature of $215{ }^{\circ} \mathrm{C}$ at 1 bar total pressure. First, a mixture of 5\% $\mathrm{H}_{2}$ in $\mathrm{He}$ (balance gas) was flowed and later a mixture of $20 \% \mathrm{O}_{2}$ in $\mathrm{He}$ was introduced to the cell. The electronic structure of iridium was probed by the Ir $4 \mathrm{f}$ line-shape by in-situ measurement of photoelectrons with $600 \mathrm{eV}$ kinetic energy by a hemispherical electron energy analyzer (see Figure 4c). XP Ir $4 \mathrm{f}_{7 / 2}$ and Ir $4 \mathrm{f}_{5 / 2}$ spectra of metallic iridium show two sharp asymmetric peaks centered at $60.9 \mathrm{eV}$ and $63.9 \mathrm{eV}$, respectively, while rutile-type $\mathrm{IrO}_{2}$ displays peaks at $61.7 \mathrm{eV}$ and $64.7 \mathrm{eV}^{20}$. Broad peak profiles indicate the presence of multiple iridium species. Figure $4 \mathrm{c}$ shows a superposition of the normalized Ir $4 \mathrm{f}$ spectra under the two gas flows described at 1 atmosphere. A broader Ir $4 \mathrm{f}$ peak evolves in the presence of oxygen at $\sim 215{ }^{\circ} \mathrm{C}$, which is related to the formation of iridium oxide species. Otherwise, the iridium is reduced in presence of $\mathrm{H}_{2}$, as the sharper peak indicates. The difference between the $\mathrm{Ir} 4 \mathrm{f}$ spectra under oxidizing and reducing atmospheres is shown in Figure $4 \mathrm{c}$ (gray curve). The difference spectrum highlights the decay in the metallic iridium contribution (peaks at $60.9 \mathrm{eV}$ and $63.9 \mathrm{eV}$ ) and the increase in the oxidized species $(61.7 \mathrm{eV}$ and $64.7 \mathrm{eV})$ in the oxidizing atmosphere. Consequently, these measurements show that the oxidation state of the sputtered Ir nanoparticles on bilayer graphene can be followed by photoelectron spectroscopy at 1 bar total gas pressure, which is a noteworthy pressure for this spectroscopic technique.

\section{III.B. Oxidation of transition metals: $\mathrm{Cu}$}

The oxidation state of sputter-deposited copper nanoparticles $(2-5 \mathrm{~nm})$ was probed by XPS and near edge X-ray absorption fine structure (NEXAFS or XAS for short) at room temperature and 1 bar total pressure. XPS was performed using the hemispherical spectrometer located at the ISISS beamline. The Cu L-edge was collected in total electron yield (TEY-XAS) by the current collected by a Faraday cup located outside of the gas cell in the main chamber (UHV). Using this approach the oxidation state of the $\mathrm{Cu}$ nanoparticles in the presence of oxidizing or reducing gases was identified. The gas mixture was monitored on-line by mass spectroscopy. Figure 5a shows the mass profile of the gas sequence flowed inside the gas cell. We started with a reducing atmosphere of $5 \% \mathrm{H}_{2}$ in $\mathrm{He}$. The sequence of exposure continues with an oxidizing atmosphere of $20 \% \mathrm{O}_{2}$ and ends with a reducing atmosphere of $5 \% \mathrm{H}_{2}$ in $\mathrm{He}$. The oxidation state of $\mathrm{Cu}$ was determined from the $\mathrm{Cu} 2 \mathrm{p}_{3 / 2}$ and $\mathrm{Cu} 2 \mathrm{p}_{1 / 2} \mathrm{XP}$ spectra (collected at $600 \mathrm{eV} \mathrm{KE}$ ), which show a broader peak in an oxidizing atmosphere than in a reducing feed (see Figure 5b). Otherwise, XAS probes the unoccupied orbitals and is sensitive to the chemical state of copper. The $\mathrm{L}_{3,2}$ edges provide unequivocal information about the oxidation state of the copper nanoparticles by characteristic $\mathrm{Cu}^{2+}$ and $\mathrm{Cu}^{+}$peaks at $\sim 931 \mathrm{eV}$ and $\sim 934 \mathrm{eV}^{21}$, respectively. Accordingly, Figure $5 \mathrm{c}$ shows the reduction of the copper nanoparticles from a $\mathrm{Cu}^{2+}$ to a $\mathrm{Cu}^{+}$state in presence of $\mathrm{H}_{2}$ at 1 bar total pressure. Switching the gases from $\mathrm{H}_{2}$ to $\mathrm{O}_{2}$, the copper nanoparticles show a slow oxidation from $\mathrm{Cu}^{+}$to $\mathrm{Cu}^{2+}$ due to the low temperature oxidation/reduction process. Finally, changing the gas back to $\mathrm{H}_{2}$ prompts the re-reduction of the copper nanoparticles. The changes 
determined as a function of the transition times for processes occurring in the oxygen and hydrogen regions have been plotted in Figure 5. Hysteresis effects can originate from several sources. Kinetically, if the rate of desorption process differs from that of the adsorption process or if the sorbate/sorbent system forms metastable domains the system undergoes an irreversible phase transition to a more stable form than before, which can yield a kinetic reaction explanation. Nevertheless, Figure S3 shows the presence of $\mathrm{Cu}$ impurities on the graphene due to the transfer process in the surface exposed to the HV (analyzer) as the $\mathrm{Cu} 2 \mathrm{p}$ spectrum collected at $200 \mathrm{eV} \mathrm{KE}$ proves (these impurities were found in $100 \%$ of the membranes analyzed $)^{18}$. It implies that the KE energy of the photoelectrons should be high enough to assure that most of the signal is coming from the $\mathrm{Cu}$ located underneath the graphene. As we mentioned above, the measurements were performed at $600 \mathrm{eV} \mathrm{KE}$ for the $\mathrm{Cu} 2 \mathrm{p}$ spectra assuring the signal is from the copper located in the side exposed to the gas.

\section{III.C. The hydrogenation of Alkynes on Pd black catalyst}

Palladium is one of the most important hydrogenation catalysts, and is industrially relevant in the selective hydrogenation of alkynes into alkenes and alkanes. A carbon-carbon triple bond can be hydrogenated partially to the alkene or fully to the alkane groups. Photoelectron spectroscopy was applied to investigate changes in the chemical nature of the active species and in particular to elucidate the electronic structure of the catalyst under reaction conditions. Online gas chromatography has been used to relate the electronic structure with the catalytic performance. Using the setup described above we explored the hydrogenation of propyne to propene and propane on a coarse sponge like form of palladium, which has a large surface area, referred to as palladium black catalyst. Figure 6 shows the $\mathrm{Pd} 3 \mathrm{~d} 5 / 2$ spectra and the gas chromatogram collected at room temperature and 1 atmosphere pressure under three different flows of gases: a) 1 atmosphere of $\mathrm{He}$, b) 1 atmosphere $41.2 \% \mathrm{H}_{2}$ in $\mathrm{He}$, c) 1 atmosphere $\mathrm{H}_{2} / \mathrm{C}_{3} \mathrm{H}_{4}(39.8 \% / 3.3 \%)$ feed gases in He. The catalytic activity of the drop casted Pd black powder (red curve in the GC spectra) was confirmed by comparison with an inactive $\mathrm{SiO}_{\mathrm{x}}$ wafer (black curve in the GC trace), as shown in Figure 6c. Photoelectron spectroscopy was applied to investigate changes in the chemical nature of the active species and, in particular, to elucidate the electronic structure of the catalyst under reaction conditions. Commercial Pd black powder was deposited on the graphene membrane by drop casting from Pd nanoparticles suspended in acetone. Figure S4 shows the absence of Pd-black particles on the part exposed to the HV (analyzer) was ruled out by the Pd $3 \mathrm{~d}$ spectra collected at different $\mathrm{KEs}^{18}$. After that the membrane was mounted in the gas cell and tested under reaction conditions. First of all, the cell was purged with a continuous flow of He and the Pd 3d5/2 spectra was collected (Figure 6a). The Pd black in the "as delivered" state in He ( 1 atmosphere) shows two peaks in the $\mathrm{Pd} 3 \mathrm{~d} 5 / 2$ spectrum. The peak at binding energy $\mathrm{BE}$ $\sim 335.0 \mathrm{eV}$ is ascribed to zero-valent metallic palladium whereas the peak at $\mathrm{BE} \sim 336.7 \mathrm{eV}$ is associated to the divalent $\mathrm{PdO}$ species. Subsequently $41.2 \% \mathrm{H}_{2}$ in $\mathrm{He}$ was flowed in the cell. The $\mathrm{H}_{2}$ was detected at the outlet of the gas line as the GC shows in the mole sieve MS5 column (Figure 6b) (VARIAN $\mu \mathrm{GC}$ 4900). Under such conditions the peak at $335.0 \mathrm{eV}$ prevails and the 
line at $336.7 \mathrm{eV}$ vanished, which indicated that the Pd catalyst was reduced ${ }^{22}$. Finally, the gas was switched to a flow mixture of $\mathrm{H}_{2} / \mathrm{C}_{3} \mathrm{H}_{4}(39.8 \% / 3.3 \%)$ in $\mathrm{He}$. The $\mathrm{Al}_{2} \mathrm{O}_{3} / \mathrm{KCl}$ column detects hydrocarbons, and the peak with the highest retention time corresponds to the educt propyne, while the first two peaks can be assigned to propane and propene, respectively. (The third peak is a butene impurity in the propyne feed.) The comparison clearly suggests that Pd black produced mainly propene and propane in smaller quantities, whereas no reactivity can be ascribed to the dummy sample. Under these conditions, Pd $3 \mathrm{~d} 5 / 2$ spectra undergoes to a shift to higher $\mathrm{BE}$ $(\sim 335.6 \mathrm{eV})$ associated with carbon incorporation into $\mathrm{Pd}\left(\mathrm{PdC}_{\mathrm{x}}\right.$ formation), which is the active phase of selective alkyne hydrogenation over $\mathrm{Pd}^{23}$.

\section{Conclusions}

A spectroscopic tool to promote knowledge-based catalyst design has been developed, built and put into operation. The system allows the investigation of the electronic structure of complex solid-gas interfaces by means of XPS at 1 bar total pressure for the first time. Higher gas pressures might become feasible in the future. Additionally, surface sensitive NEXAFS measurements in the electron yield mode are feasible with the very same cell without any modification. This design overcomes the limit of AP-XPS by allowing the analysis of the electronic structure of complex systems under real atmospheric pressure without the need for a special (i.e. differentially pumped) electron spectrometer since the pressure during operation of the gas cell in the vacuum tank remains around $10^{-6}$ mbar. Therefore, this cell design opens up the possibility of reaction studies at higher pressure overcoming the so-called "pressure gap", which, among other areas, is of prime importance for catalysis and environmental science. These measurements are possible due to the excellent photoelectron transmission, as well as the outstanding properties of graphene such as leak tightness and photoelectron transparency.

\section{Acknowledgements}

We thank to the staff at BESSY II of the HZB for operational support. HZB is acknowledged for granting beamtime at the ISISS endstation under proposal \#14201159. This work was funded from EU project GRAFOL grant 285275. We thank Ministry of Education and Science of the Russian Federation (agreement \#14.616.21.0007) and Bundesministerium für Bildung und Forschung (project \#05K2014) for financial support in the framework of joint Russian-German research project "SYnchrotron and NEutron STudies for Energy Storage (SYNESTESia)". We thanks Dr. Mark Greiner and Dr. Travis Jones for helping during the manuscript preparation.

\section{References}

${ }^{1}$ J. J. Berzelius, Årsberättelsen om framsteg i fysik och kemi, Annual report on progress in physics and chemistry,. Stockholm, Sweden: Royal Swedish Academy of Sciences (1985).

${ }^{2}$ C. N. Satterfield, Heterogeneous catalysis in industrial practice. $2^{\text {nd }}$ Edition (1991) . 
${ }^{3}$ N. Yamazoe, Sens. and Act. B: Chemical 5(1), 7-19 (1991).

${ }^{4}$ E. J. Henley, J. D. Seader, and D. K. Roper, Separation process principles. Wiley (2011).

${ }^{5}$ L. Carrette, K. A. Friedrich, and U. Stimming, Fuel cells, 1(1), 5-39 (2011).

${ }^{6}$ C. H. Wong, and G. M. Whitesides, Enzymes in synthetic organic chemistry (Vol. 12). Academic Press (1994).

${ }^{7}$ R. Schlögl, Ang. Chem. Int. Ed. 50(29), 6424-6426 (2011).

${ }^{8}$ P. Stoltze, and J. K. Nørskov, Phys. Rev. Lett. 55(22), 2502 (1985).

${ }^{9}$ D. F. Ogletree, H. Bluhm, G. Lebedev, C. S. Fadley, Z. Hussain, and M. Salmeron, Rev. of Sci. Ins. 73(11), 3872-3877 (2002).

${ }^{10}$ S. Kaya, H. Ogasawara, L.A. Näslund, J.O. Forsell, H.S. Casalongue, D. J. Miller, A. Nilsson, Cat. Tod. 205, 101-105, (2013).

${ }^{11}$ S. Axnanda, E.J. Crumlin, B. Mao, S. Rani, R. Chang, P.G. Karlsson, M.O.M. Edwards, M. Lundqvist, R. Moberg, P.N. Ross, Z. Husssain, Z. Liu, Sci. Rep. 5, 9788 (2015).

${ }^{12}$ A. Knop-Gericke, M. Hävecker, T. Neisius, and T. Schedel-Niedrig, Nuc. Ins. and Meth. in Phys. Res. Sec. A 406(2), 311-322 (1998).

${ }^{13}$ J. J. Velasco-Velez, C.H. Wu, T.A. Pascal, L. Wan, J. Guo, D. Predergast, and M. Salmeron, Science 346(6211), 831-834 (2014).

${ }^{14}$ K. Siegbahn, Electron spectroscopy for atoms, molecules and condensed matter. Uppsala Univ.(Sweden). Fysiska Institutionen (1981).

${ }^{15}$ J. J. Velasco-Velez, V. Pfeifer, M. Hävecker, R. S. Weatherup, R. Arrigo, C.-H. Chuang, E. Stotz, G. Weinberg, R. Schlögl, and A. Knop-Gericke, Ang. Chem. Int. Edit. 54(48), 1455414558 (2015).

${ }^{16}$ https://www.helmholtz-berlin.de/pubbin/igama_output?modus=einzel\&sprache=en \&gid=1607

${ }^{17}$ C. Heine, M. Hävecker, E. Stotz, F. Rosowski, A. Knop-Gericke, A. Trunschke, M. Eichelbaum, and R. Schlögl, J. Phys. Chem. 118, 20405 (2014).

${ }^{18}$ See supplemental material at [URL will be inserted by AIP] for the leak test and for the element depth profile obtained at different KEs .

${ }^{19}$ A. Kolmakov, L. Gregoratti, M. Kiskinova and S. Günther, Top. Cat. 59, 448-468 (2016).

${ }^{20}$ C. S. Fadley, and D. A. Shirley, J. Res. Natl. Bur. Stand. A 74, 543 (1970).

${ }^{21}$ G. Vlaic, J. C. J. Bart, W. Cavigiolo, and S. Mobilo, Chem. Phys. Lett. 76(3), 453-459 (1980).

${ }^{22}$ K. Noack, H. Zbinden, and R. Schlögl, Cat. Lett. 4(2), 145-155 (1990).

${ }^{23}$ D. Teschner, J. Borsodi, A. Wootsch, Z. Révay, M. Hävecker, A Knop-Gericke, S. D. Jackson, and R. Schlögl, Science 320(5872), 86-89 (2008). 


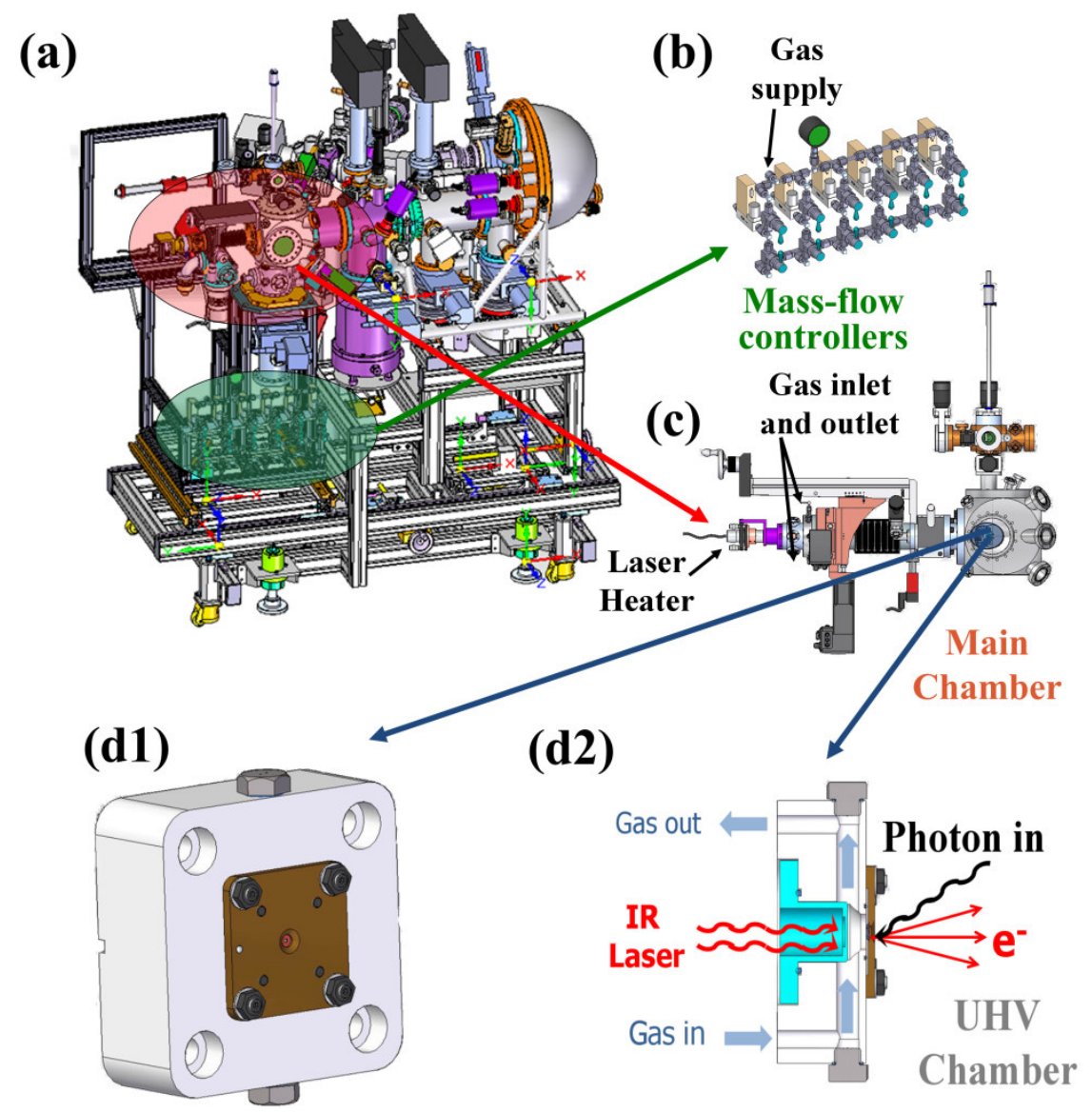

Figure 1: a) AP-XPS set-up. b) Mass flow controllers. c) Main-chamber including the manipulator. d1) Gas cell inlay including d2)its cross section.

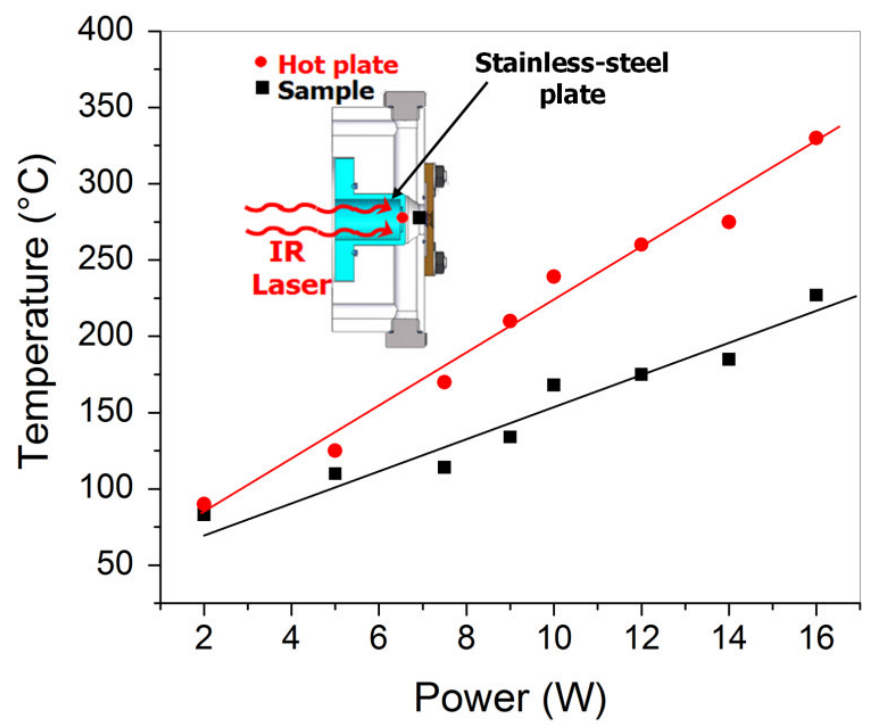

Figure 2: Temperatures in the hot plate and in the sample versus laser power. 

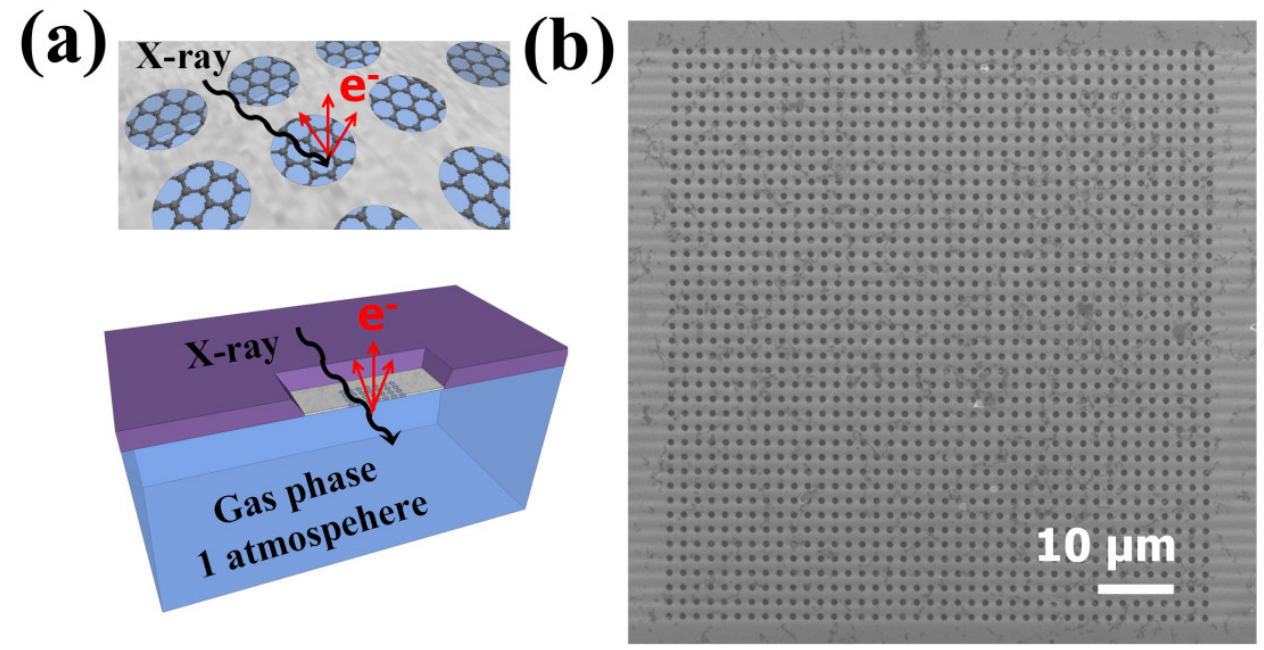

Figure 3: a) Membrane sketch. b) SEM image of the holes array ( $80 \mu \mathrm{m} \times 80 \mu \mathrm{m}$ array with one $1 \mu \mathrm{m}$ diameter holes ) fully coated by a bi-layer graphene (BLG).
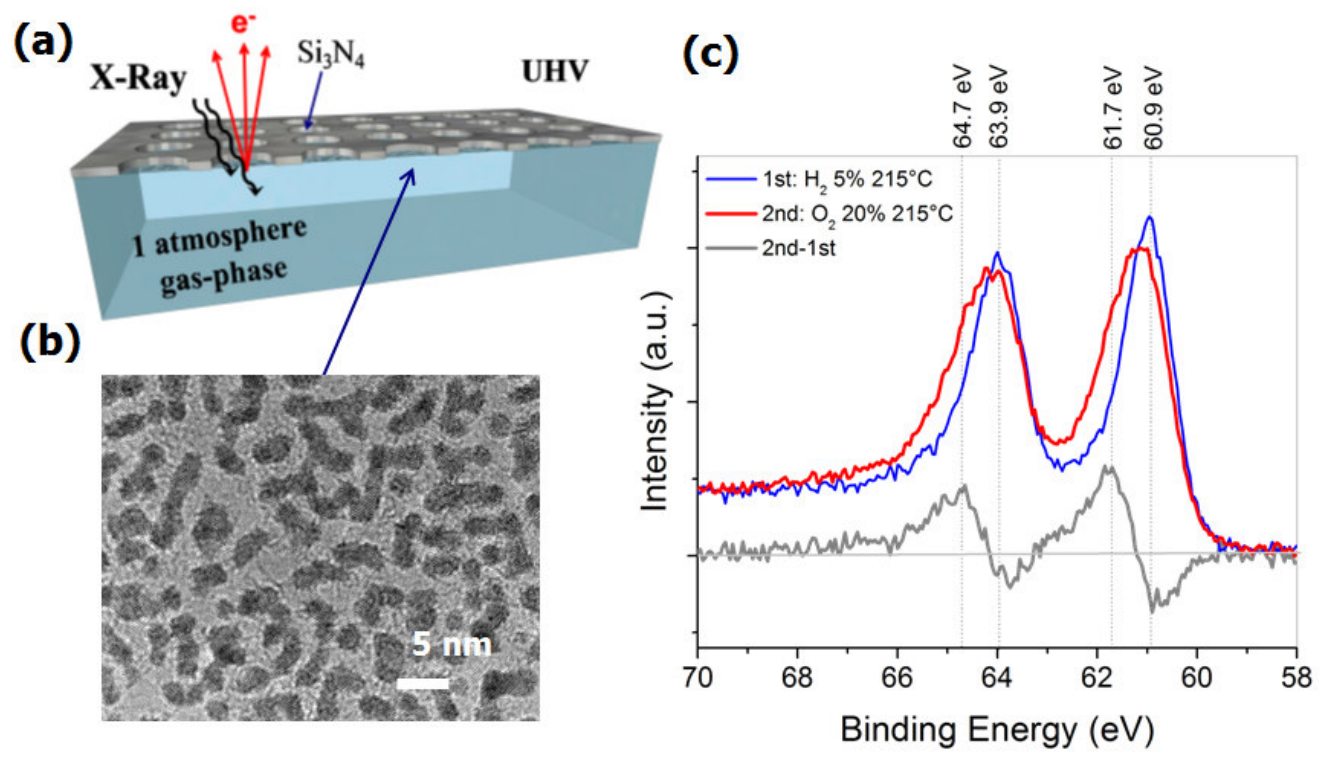

Figure 4: a) Schematic of the operation mode including b) TEM measurement of the sputtered nanoparticles on BLG $(2-5 \mathrm{~nm})$ and $\mathrm{c})$ the $\mathrm{Ir} 4 \mathrm{f} \mathrm{XP}$ spectra under several gases exposures $(\mathrm{P}=1 \mathrm{bar}, \mathrm{T}=$ $\left.25^{\circ} \mathrm{C}\right)$. 

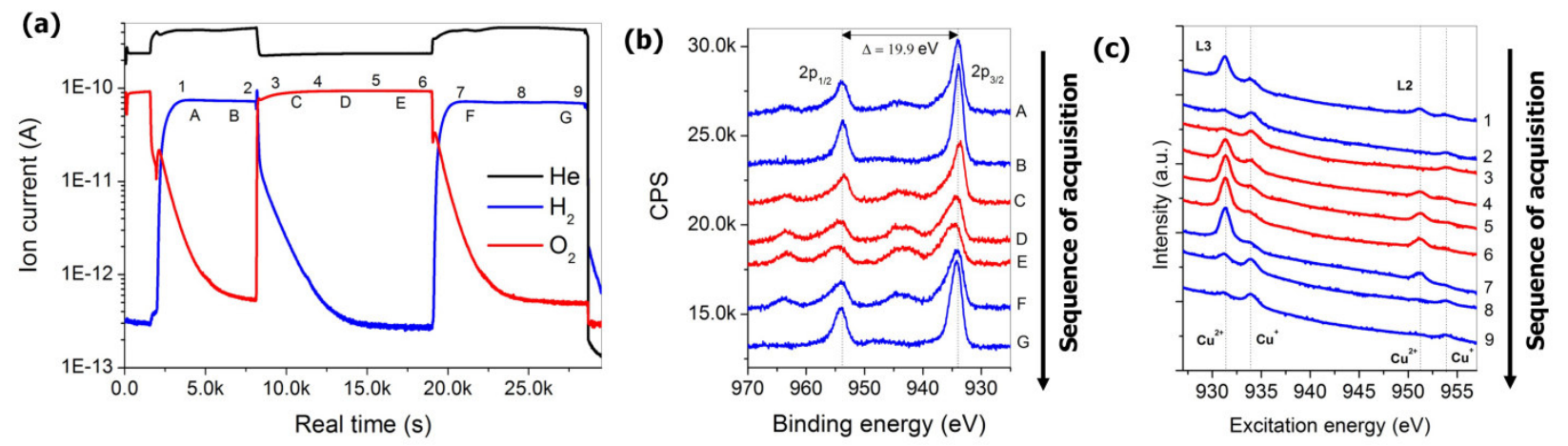

Figure 5: a) Mass spectra collected under different gas exposure. b) $\mathrm{Cu} 2 \mathrm{p} \mathrm{XP}$ and c) $\mathrm{Cu}_{3,2}$-edges XA spectra under different gas exposure $\left(\mathrm{P}=1 \mathrm{bar}, \mathrm{T}=25^{\circ} \mathrm{C}\right)$.

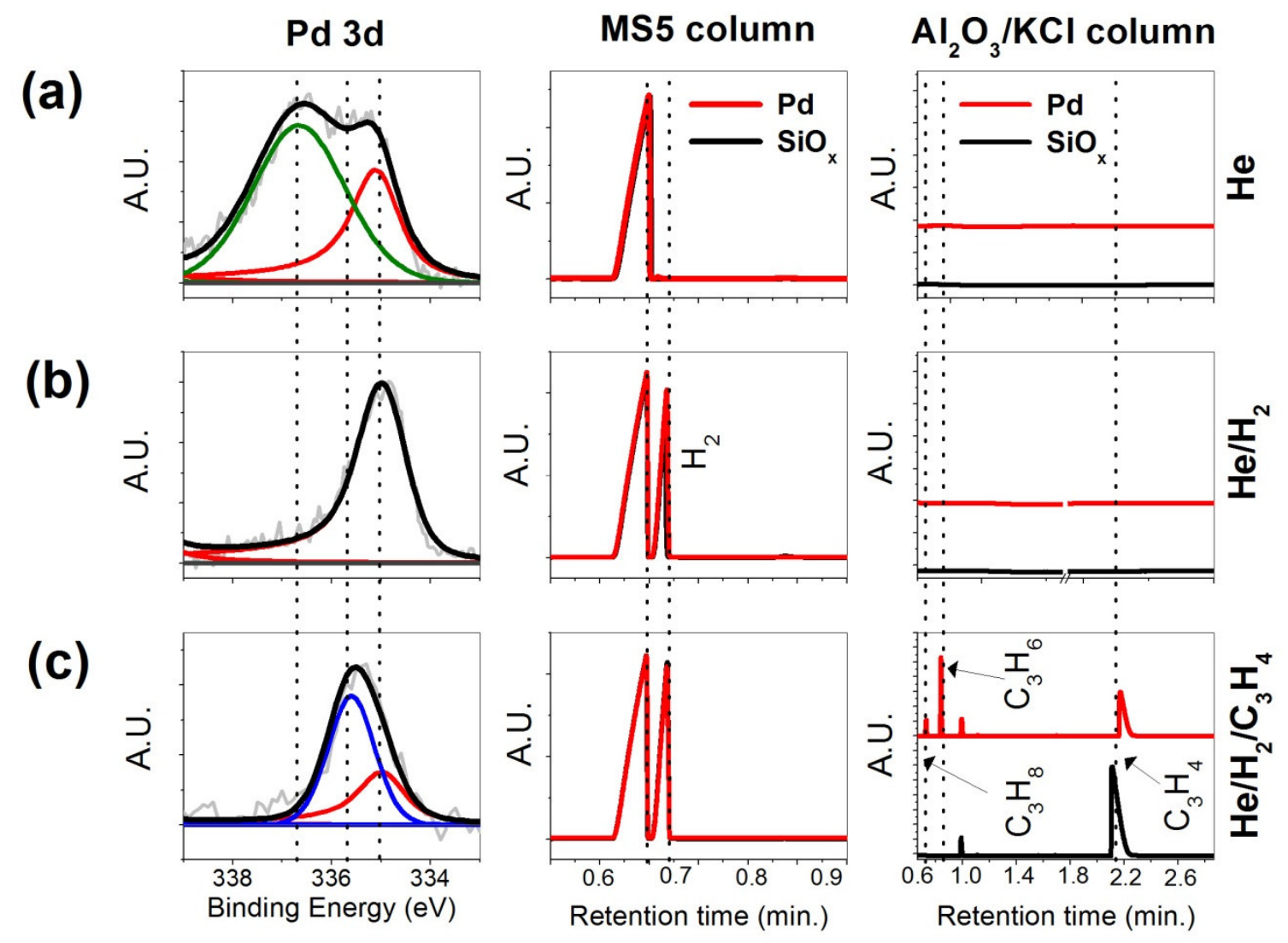

Figure 6: a) Pd 3d XP spectra and gas chromatography traces (VARIAN $\mu$ GC 4900) using a mol sieve MS5 column (VARIAN CP740148) and $\mathrm{Al}_{2} \mathrm{O}_{3} / \mathrm{KCl}$ column(AGILENT 494001440) : a) $\mathrm{He}, \mathrm{b}$ ) $\mathrm{He} / \mathrm{H}_{2}$, and c) $\mathrm{He} / \mathrm{H}_{2} / \mathrm{C}_{3} \mathrm{H}_{4}$ gas mixtures. 


\section{Supplemental material}

\section{Atmospheric pressure X-ray photoelectron spectroscopy}

\section{apparatus: Bridging the pressure gap}

J. J. Velasco-Vélez ${ }^{1,2, *}$, V. Pfeifer ${ }^{2}$, M. Hävecker ${ }^{1, *}$, R. Wang $^{3}$, A. Centeno ${ }^{4}$, A. Zurutuza ${ }^{4}$, G. Algara-Siller ${ }^{2}$, E. Stotz ${ }^{2}$, K. Skorupska ${ }^{1}$, D. Teschner ${ }^{2}$, P. Kube ${ }^{2}$, P. Braeuninger-Weimer, S.

Hofmann, R. Schlögl ${ }^{1,2}$ and A. Knop-Gericke ${ }^{2}$

*Corresponding authors: velasco@ fhi-berlin.mpg.de and mh@fhi-berlin.mpg.de

${ }^{1}$ Department of Heterogeneous Reactions, Max Planck Institute for Chemical Energy Conversion, Mülheim an der Ruhr 45470, Germany

${ }^{2}$ Department of Inorganic Chemistry, Fritz-Haber-Insitut der Max-Planck-Gesellschaft, Berlin 14195, Germany

${ }^{3}$ Engineering Department, University of Cambridge, Cambridge CB3 0FA, United Kingdom

${ }^{4}$ Graphenea, San Sebastian 20018, Spain

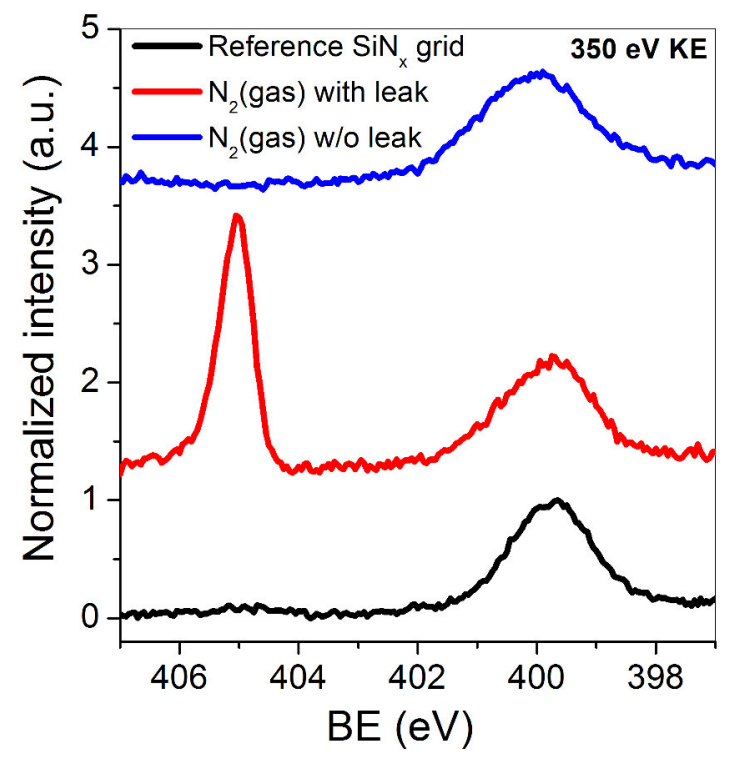

Figure S1: N 1s spectra collected in presence of $100 \% \mathrm{~N}_{2}$ gas for a leak (red curve) and leak-tight (blue curve) membrane collected at $350 \mathrm{eV} \mathrm{KE}$. 


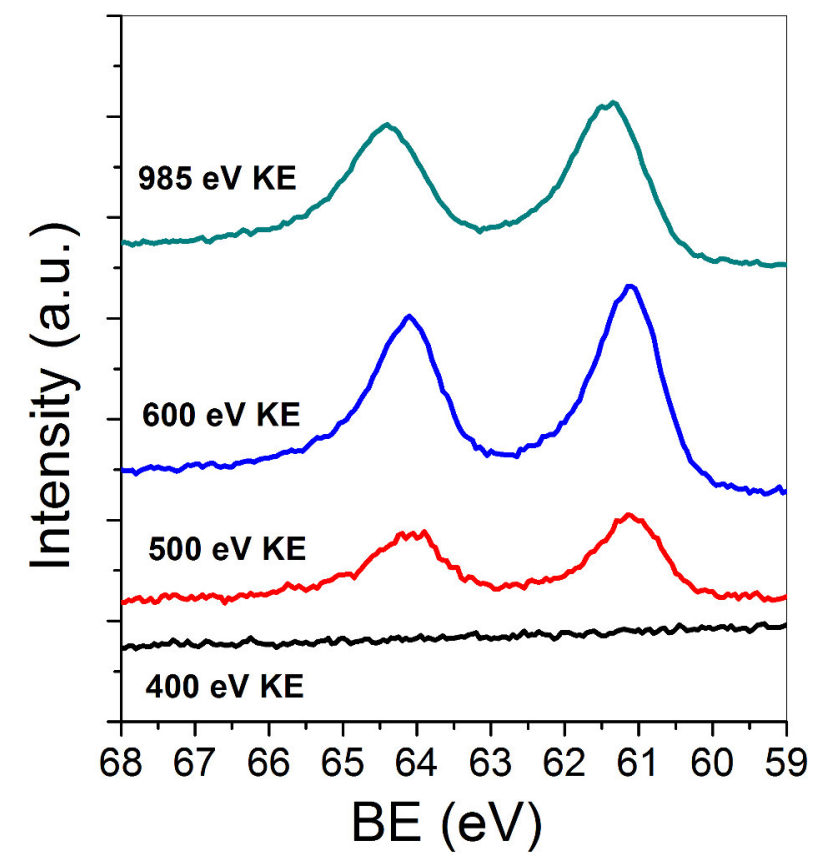

Figure S2: Ir 4f spectra of the sputtered deposited iridium nano-particles collected at different KEs $\left(\mathrm{P}=1\right.$ bar in $\left.\mathrm{He}, \mathrm{T}=25^{\circ} \mathrm{C}\right)$.

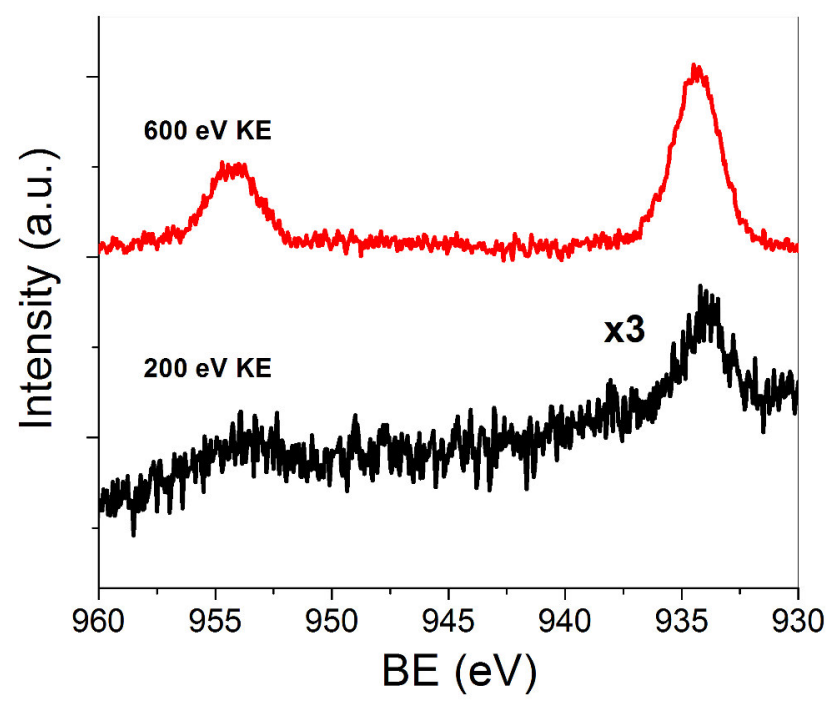

Figure S3: $\mathrm{Cu} 2 \mathrm{p}$ spectra of the sputtered deposited copper nano-particles collected at different KEs. The $\mathrm{Cu} 2 \mathrm{p}$ spectrum collected at $200 \mathrm{eV} \mathrm{KE}\left(\mathrm{P}=1 \mathrm{bar}\right.$ in $\left.\mathrm{He}, \mathrm{T}=25{ }^{\circ} \mathrm{C}\right)$ indicates the existence of copper residues from the graphene transfer process.. 


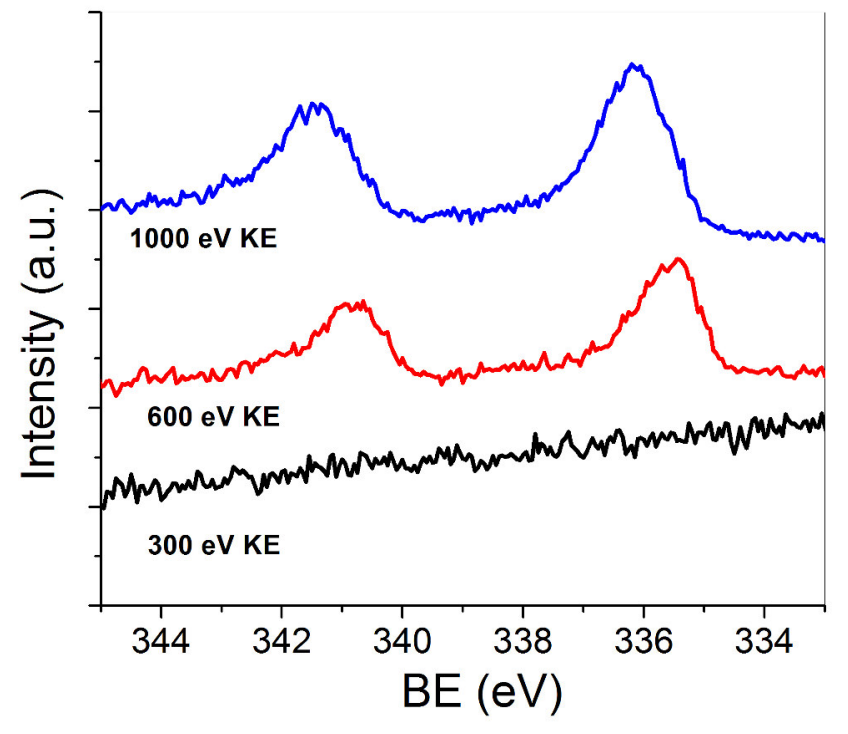

Figure S4: Pd 3d spectra of the hydrogenated Pd-black catalyst deposited by drop casting and collected at different $\mathrm{KEs}\left(\mathrm{P}=1\right.$ bar, $41.2 \% \mathrm{H}_{2}$ in $\left.\mathrm{He}, \mathrm{T}=25^{\circ} \mathrm{C}\right)$. 